\title{
Pabllo Vittar e a representatividade lgbtqia+ na publicidade: uma análise sobre as formas de consumo pós-modernas
}

\author{
Pabllo Vittar and lgbtqia+ representativeness in advertising: an analysis of \\ postmodern ways of consumption
}

\author{
Eduardo Bianchi ${ }^{l}$ \\ Thiago do Nascimento Lima ${ }^{2}$
}

\begin{abstract}
RESUMO:
Este trabalho tem como objetivo observar os desdobramentos causados pela introdução de novas projeções sobre a comunidade LGBTQIA+ no mercado publicitário, com enfoque nas narrativas que incluam como protagonista a drag queen Pabllo Vittar. O processo de sociabilidade desta comunidade, por vezes, foi impactado negativamente diante do contexto social e político ao qual foi exposto, restringindo o espaço de seus integrantes. Sendo assim, foi posta à prova a capacidade que a publicidade teria de influenciar este quadro, através da representatividade desses sujeitos por intermédio de Pabllo Vittar. As relações comunicacionais que envolvem essas campanhas também foram analisadas, com o propósito de se entender as novas formas de consumo que acompanham as identidades pósmodernas, examinando-se suas performances nos meios midiáticos, e, em seguida, contextualizou-se o case 'Quem disse, Berenice?', que é inserido no clipe Disk Me de Pabllo Vittar.
\end{abstract}

Palavras-Chave: Pabllo Vittar; Representatividade; Comunidade LGBTQIA+; Drag Queen; 'Quem disse, Berenice?'.

\begin{abstract}
This paper aims to analyze the consequences caused by the introduction of new views on LGBTQIA+ community at the advertising market, focusing on the narratives that put the drag queen Pabllo Vittar as the protagonist. The sociability process of the LGBTQIA+ community has been, most of the times, negatively impacted due to the social and political context to which it was exposed, reducing the space of its members. Consequently, the capacity that the advertising would have to influence in this context, throughout the representativeness of these subjects through Pabllo Vittar. The communicational relations that are related to these advertising campaigns were also analyzed with the purpose to understand new forms of consumption that follow postmodern identities, first understanding the concepts of contemporary advertising techniques and evaluating their performances in the media, and then applying survey metrics in a LGBTQIA+ field sample about the 'Quem disse, Berenice?' case, which is inserted on Pabllo Vittar's Disk Me video clip.
\end{abstract}

Keywords: Pabllo Vittar; Representativeness; LGBTQIA+ community; Drag Queen; 'Quem disse, Berenice?'.

\footnotetext{
${ }^{1}$ Doutor em Comunicação pela Universidade do Estado do Rio de Janeiro, membro de grupo de pesquisa Comunicação, Arte e Cultura - CAC/UERJ, professor do curso de Comunicação da Universidade Veiga de Almeida - UVA. eduardo.bianchi.cs@gmail.com

${ }^{2}$ Publicitário formado pela Universidade Veiga de Almeida. thiago@marketingup.com.br
} 


\section{Introdução}

Recorreu-se à pesquisa elaborada por Amanajás (2015) para se traçar uma linha do tempo sobre a expressão artística, política e social das drag queens ${ }^{3}$, compreendendo os papéis exercidos por essa manifestação artística, que sofreu o massacrante impacto do julgamento social ao longo do tempo. O percurso descrito por Amanajás (2015) conduziu este artigo durante sua primeira parte e permitiu que se problematizasse a chegada da importante década de 1960, repleta de movimentos sociointelectuais e contraculturais, os quais respaldaram a (re)configuração do que se entende por "identidade pós-moderna"4, permitindo que hoje a comunidade LGBT$\mathrm{QIA}+{ }^{5}$ tenha novas oportunidades de sociabilidade entre seus grupos e socialização na reinvindicação de suas cidadanias para evidenciar seus modos de viver, ser e estar no mundo. Aliados a essas transformações, novos espaços de manifestação cultural e artística

\footnotetext{
3 "Artistas que fazem uso de feminilidade estereotipada e exacerbada em apresentações são conhecidos como drag queens, que são homens fantasiados como mulheres. (...) $\mathrm{O}$ termo mais antigo, usado no Brasil para tratálos, é o de artistas transformistas. Drag queens/king são transformistas, vivenciam a inversão do gênero como diversão, entretenimento e espetáculo, não como identidade." (JESUS, 2012, p. 18)

4 O conceito de "identidade pós-moderna" apresentado nesta pesquisa está baseado em Stuart Hall (2006) e será mais bem definido e desdobrado ao longo do artigo.

${ }^{5}$ LGBTQIA+ é a sigla usada para representar Lésbicas, Gays, Bissexuais, Transexuais e Travestis, Queers, Intersexuais, Assexuados, e "+" representa outros grupos que não se identificam com o binarismo heterossexual.
}

surgiram, neles, os Ballrooms $^{6}$, que funcionavam como um campo livre para a manifestação drag. Salienta-se que, mesmo que tal processo esteja em andamento, muitos aspectos ainda são limitados pelas resistências de dominação histórica heterossexual, binária e machista.

Este trabalho se propõe a analisar o amadurecimento artístico e pessoal de Pabllo Vittar, homem gay e artista que performa na arte das drag queens ${ }^{7}$. Phabullo Rodrigues da Silva é o sujeito por trás das performances da drag Pabllo Vittar. Homossexual, desde criança "afeminado", sempre esteve em contato com as dificuldades enfrentadas por esse grupo minoritário, subjugado pelos padrões heteronormativos. Contudo, antes de entrar em tal recorte, o objeto da pesquisa demandou um debruçar mais profundo sobre a cultura drag e suas transformações históricas.

Buscou-se, na metáfora que Louro (2008) faz sobre "viagem", uma relação entre amadurecimento e descoberta de identidade de Pabllo Vittar. Tal viagem deve ser percebida como processo de formação pessoal que ocorre pelas experiências e pelas possibilidades de escolhas que, no caso

\footnotetext{
6 “Os Ballrooms, cuja origem data em meados do fim da década de 1970 na cidade de Nova York, mas que provém das práticas dos bailes de fantasia e drag queen iniciados no começo do século XX, é uma cultura LGBT baseada em práticas de performance, competições e estruturas de apoio social e emocional para seus membros" (SANTOS, 2018, p. 10).

7 Usaremos por diversas vezes a expressão drag, em detrimento de drag queen, pois é dessa forma que os membros do grupo artístico e pessoas relacionadas denominam.
} 
desta pesquisa, Pabllo Vittar vem fazendo e evidenciando com sua imagem pública.

No início da carreira de Phabullo Rodrigues da Silva, aos 13 anos, em suas primeiras aparições em programas regionais, quando começou a dar voz à sua drag, já se evidenciava um rompimento com padrões socialmente definidos. Recorremos ao trabalho de Preciado (2017) e suas reflexões sobre a contrassexualidade para analisar Pabllo Vittar: a "contrassexualidade é também uma teoria do corpo que se situa fora das oposições homem/mulher, masculino/feminino, heterossexualida-

de/homossexualidade" (PRECIADO, 2017, p.22). Dessa forma, observamos a orientação contrassexual de Pablo Vittar, como, por exemplo, a indiferença em relação ao gênero e a negação de padrões dicotômicos. Como já declarado ${ }^{8}$ pela própria cantora, "Vamos deixar uma coisa aqui clara! Essa coisa de gênero é muito 2005" (VITTAR, 2018, $2 \mathrm{~min}$ ), do mesmo modo que compara a relação de prazeres que não necessariamente estão ligados ao ato sexual, mas que podem se manifestar em diversos momentos que permeiam a performance de Pabllo e de outras drags.

Para analisarmos a popularização da persona Pabllo Vittar e seu trabalho artístico, faz-se necessário observar as potências comunicacionais de nossa sociedade, aqui destacadas

\footnotetext{
${ }^{8}$ Entrevista para o programa Conexão Repórter. Disponível em: $<$ https://www.youtube.com/watch?v $=$ XFEXjAyw9t8>. Acesso em: 28 de agosto de 2018.
}

pelo importante papel das Tecnologias de Informação e Comunicação (TICs) como ferramentas usadas para reivindicar espaço de fala. As apropriações dessas tecnologias foram e são importantes ferramentas para que os LGBT$\mathrm{QIA}+$ possam se reconhecer e trocar suas experiências e, dessa forma, não se sentirem excluídos ou menosprezados. Destacam-se, ainda, nesta pesquisa, as formas de consumo, e recorremos à teoria da convergência das mídias e das culturas de Jenkins (2006) para pensar os processos relacionais entre a arte drag, as performances de Pabllo Vittar e os produtos que ela passou a representar como garota propaganda. As colaborações desse entendimento se fazem necessárias para imergirmos no estudo de caso sobre a inserção da marca 'Quem disse, Berenice?' no clipe Disk me de Pabllo Vittar.

\section{Apresentação da Cultura Drag Queen}

Observa-se uma pluralidade de performances no cenário artístico mundial, e o mercado brasileiro segue os mesmos passos na abertura de espaços para categorias que anteriormente eram restritas somente a meios e públicos específicos, grupos que apresentavam práticas sociais ligadas mais diretamente ao estilo de vida da performance que consumiam. $\mathrm{O}$ meio publicitário, por sua vez, faz-se valer de certas personalidades e narrativas para construir as imagens de seus produtos. Pode-se observar uma crescente adequação aos diversos contextos e grupos sociais. Em um deles, encon- 
tram-se as drag queens, uma manifestação artística que sofreu intensas transformações durante toda a história, principalmente em relação ao seu comportamento e ao espaço social que ocupa. A primeira vez que a figura de um homem travestido de mulher se apresentou em um cenário artístico data do período da Grécia Antiga (BERTHOLD, 2004), quando foram estruturados os primeiros teatros. Nesse contexto, máscaras eram utilizadas para representar as figuras masculinas e femininas, porém, somente homens poderiam interpretá-las.

As máscaras eram insuficientes para a transmissão de personagens femininos. Então, segundo Amanajás (2015), grandes personagens da mitologia grega eram interpretadas por homens que também usavam roupas e enchimentos para compor a imagem feminina. Assim, nota-se o aparecimento das primeiras referências do mundo Drag: "vestir-se como". Após a Idade Média, que foi um período obscuro para artes efêmeras, entre elas, o teatro, mulheres já ocupavam em menor proporção a cena teatral, executando pequenos papéis, porém, os de protagonistas e de destaque ainda eram interpretados por atores masculinos mais jovens.

A permissão definitiva para as mulheres subirem aos palcos e interpretarem papéis femininos mais complexos foi concedida por Carlos $\mathrm{II}^{9}$, conforme afirma Baker (1994). Nesse

\footnotetext{
${ }^{9}$ Monarca inglês adepto do absolutismo, assumiu o trono entre 1660 e 1685 , mesmo ano de sua morte. Disponível em: < https://www.royal.uk/charles-ii>. Acesso em: 28 de agosto de 2018.
}

contexto, as "Drags" ocupavam cada vez menos espaço no teatro, e, fora de cena, abriram espaço para as Drags seculares, figuras como a dona de casa fofoqueira, a mulher feia que nunca iria arrumar um companheiro, enfermeiras e vendedoras de flores, que, segundo Baker (1994), consistiam em uma segunda linha de Drags. Baker (1994) apresenta diversos relatos de casos de crossdressers $^{10}$, homens se apropriando de luxuosas roupas femininas e desfilando pelas ruas. Nessa época, o código de vestimenta deixou de ser atribuído ao status social e ao gênero e começou a desenhar-se o conceito de moda, iniciando-se, assim, uma concepção errada em relacionar a drag queen à homossexualidade, aditivada por parâmetros sociais e religiosos: "No final do século XVII, o ator feminino havia se tornado uma figura cômica, uma criatura do burlesco e da paródia" (BAKER, 1994, p.161). Nos próximos 150 anos, sua aparição foi esporádica, mas o retorno à cena se deu no século XIX, quando ocuparam um espaço cômico, em sua maioria no teatro. Tal figura era conhecida como a dama pantomímica, como cita Amanajás. Ainda conforme afirma Amanajás (2015, p. 14), a dama pantomímica foi a única forma de drag queen existente

\footnotetext{
10 "Surgiu um termo novo, variante de travesti, para se referir a homens heterossexuais, geralmente casados, que não buscam reconhecimento e tratamento de gênero (não são transexuais), mas, apesar de vivenciarem diferentes papéis de gênero, tendo prazer ao se vestirem como mulheres, sentem-se como pertencentes ao gênero que lhes foi atribuído ao nascimento, e não se consideram travestis" (JESUS, 2012, p.12).
} 
na primeira metade do século $\mathrm{XX}$. Ainda vista com bons olhos perante a sociedade, era bem recebida e já era de costume que todo ator comediante tivesse uma drag entre seus personagens.

Durante o início do século XX, certa movimentação nos guetos novaiorquinos, principalmente no Harlem, tomava conta das ruas e anunciava o que seria o começo dos chamados Ballrooms (HUGHES, 1993). Eram comuns nas áreas mais periféricas reuniões de grupos marginalizados que referendavam o travestismo. Inicialmente eram bailes de máscaras em que os participantes eram em sua maioria homossexuais, como cita Venuti (2011). Na década de 1920, esses eventos já faziam parte da cultura underground daquela região. As práticas desses encontros já eram frequentes e sofriam resistência social, pois o ato de se travestir era considerado contra a lei. Os participantes desses bailes estavam ali sujeitos à "higienização" social. O contexto de repreensão pósguerra era intenso, mas, de acordo com Santos (2018), isso não impediu que as reuniões continuassem a ser realizadas. Segundo Santos (2018), em meados da década de 1960, os frequentes conflitos étnicos se instauravam nos bailes, e era majoritária a presença de brancos, fazendo com que os participantes negros se adequassem aos padrões brancos para ganharem os prêmios das competições realizadas durante os bailes. O que gerava insatisfação e levou os candidatos negros a formarem seus próprios encontros, adequando o for- mato para a realidade vivida por eles e acrescentando novas rotinas aos encontros, como, por exemplo, a implantação do Voguing ${ }^{11}$ e outras categorias de competições.

Como cita Bailey (2013), três aspectos são a base da cultura dos Ballrooms: o sistema de gênero; a estrutura familiar reconhecida como Houses; e as competições de categorias nos chamados balls. O que torna, para Santos (2018), essa estrutura bem mais complexa que os antigos bailes promovidos por brancos, agregando a esse ambiente uma atmosfera de cultura e identidade: "tal estrutura justifica a escolha feita aqui de se chamar toda essa dinâmica como a cultura dos Ballrooms, já que, segundo seus participantes, os balls são muito mais do que as competições, mas sim um estilo de vida" (SANTOS, 2018, p.16).

Em Paris is Burning, um documentário da década de 1990, mas produzido no período de 1987 a 1989 , a diretora e produtora Jennie Livingston busca retratar a cena dos balls nova-iorquinos, mesclando cenas gravadas nos próprios ballrooms e entrevistas das participantes nessa época ${ }^{12}$. $\mathrm{O}$ documentário aborda assuntos como a importância dos balls na vida dos partícipes, os conflitos sociais marcantes da década de 1980, o linguajar usado nos bailes - presentes até hoje na cul-

${ }^{11}$ Segundo Venuti (2011), um estilo de dança que nasceu do ritual praticado pelas drag queens, nas regiões periféricas de Nova Iorque, de insultar umas às outras de maneira sutil e provocativa.

12 Pepper LaBeija, Dorian Corey, Willi Ninja, Venus Xtravaganza, Octavia St. Laurent, entre outras. 
tura drag, como, por exemplo, nos bordões utilizados por RuPaul ${ }^{13} \mathrm{em}$ seu programa RuPaul's Drag Race e seus participantes - e acompanha a ascensão de algumas tendências surgidas nos guetos e emersas nos bailes.

"Faça uma pose. Vogue!" (MADONNA, 1990). Os primeiros versos da música de Madonna, lançada duas semanas após o documentário Paris is Burning, fazem uma fiel referência à categoria disputada nos balls. Nesse contexto, é percebido certo entusiasmo midiático com a cultura dos Ballrooms, em que, a reboque da visibilidade da cantora, torna massificado o consumo desse estilo de dança. É a primeira vez que as drags periféricas de Nova Iorque se veem representadas no mainstream. Tal mudança paradigmática do gueto para os holofotes da cultura de massa, causada não só por Madonna e sua música Vogue, mas também por diversos meios, como o cinema e a televisão, que permitiram a visibilidade de atores sociais que não se encaixavam nos moldes de comportamentos heteronormativos, reverberou nas mais diversas esferas comunicacionais.

De certo modo, aquela onda de liberdade propagou a discussão sobre sexualidade, identidade e comporta-

\footnotetext{
${ }^{13}$ Ator, apresentador, compositor, cantor, modelo, que em 1993 alcançou reconhecimento internacional com sua música Supermodel (You better work), como apontam os arquivos da Billboard. A página se encontra digitalizada e disponível em: <https://www.americanradiohistory.com/Archi ve-Billboard/ 90s/1993/BB-1993-0605.pdf\#page $=109>$. Acesso em: 12 de setembro de 2018.
}

mento de uma maneira ainda desconhecida pela sociedade, pautada nos estudos de Foucault ${ }^{14}$ sobre o modelo de discurso, saber e poder - o primeiro para além do conhecimento, que, segundo Foucault, é molecular, portanto em transformação, já o segundo está em um sistema de negociação e disputa, o que é denominado como "jogo de poder”. Segundo Spargo (2017), a sexualidade não é mais um campo restrito e cheio de pudores, ainda que possamos identificar resistências às transformações de nosso tempo em grupos sociais conservadores. Muitos desses movimentos buscam a manutenção de raízes normativas para os papéis sociais e suas performatividades ${ }^{15}$. Tais movimentos são, em muitos casos, encabeçados por líderes religiosos e representantes políticos, como Damares Alves, pastora evangélica e atual ministra da mulher, da família e dos direitos humanos do governo Jair Bolsonaro, que defende publicamente que meninos devem vestir azul e meninas rosa ${ }^{16}$, como se fosse do âmbito do natural a relação da masculinidade e feminilidade serem determinadas por certos aspectos, como as cores que usam. Em entrevista, antes de assumir

\footnotetext{
${ }^{14}$ A autora Tasmin Spargo faz uma análise das ideias de Foucault no texto História da sexualidade: a vontade de saber (1976).

15 Veremos a seguir o conceito de performatividade a partir de Butler (2003).

16 MENINO veste azul e menina veste rosa, diz Damares Alves em vídeo. O Globo. Disponível em: <https://oglobo.globo.com/sociedade/meninoveste-azul-menina-veste-rosa-diz-damaresalves-em-video-23343024>. Acesso em: 28 de fevereiro de 2019
} 
o ministério, Damares declarou que "as mulheres nasceram para serem mães e que o modelo ideal de sociedade as deixaria apenas em casa, sustentadas pelos homens"17. Mesmo que existam muitas pessoas que comunguem com ideias como as de Damares, existem muitos outros que estão dispostos a se evidenciarem, pessoas comuns que se colocam no mundo reivindicando seus direitos de existir e de cidadania. Cada LGBTQIA+ que sai à rua apresentando seu corpo tomado de subjetividades em fuga à heteronomatividade está fazendo política, por vezes intencionalmente e, em outros casos, nem mesmo sabendo que estão lutando por igualdade e reivindicando sua vivência.

Spargo (2017) menciona o interesse de acadêmicos que se dedicaram a elaborar uma série de estudos, nos mais diversos campos das humanidades, para abordar a relação da comunidade LGBTQIA+, durante a década de 1980, quando ainda não reconhecida em toda sua pluralidade de identidades, e desenvolver uma série de debates que resultaram no que é denominado de teoria queer.

Como seria de se esperar, a teoria queer não tem origem em um momento isolado, mas, retrospectivamente, costuma-se dizer que seu início se cristalizou a partir de uma

17 COTADA para ministra diz que mulher nasce para ser mãe e infelizmente tem que ir para o mercado de trabalho. O Globo. Disponível em: <https://oglobo.globo.com/brasil/cotada-paraministra-diz-que-mulher -nasce-para-ser-maeinfelizmente-tem-que-ir-para-mercado-detrabalho-23272762>. Acesso em: 28de setembro de 2019. série de conferências acadêmicas que, nos Estados Unidos, no fim dos anos 1980, abordaram a relação de questões gays e lésbicas com as teorias pós-estruturalistas ${ }^{18}$. (SPARGO, 2017, p.30)

A apropriação do termo queer, segundo Spargo (2017), deu-se pela atuação de grupos de resistência, como o ACT UP ${ }^{19}$, e também por artifícios de ativismo. O termo, que até o momento era usado para inferiorizar e causar repúdio, foi ressignificado para demonstrar relutância por parte da própria comunidade. A teoria queer provoca questionamentos feitos por Spargo (2017), tendo como base os pensamentos de Foucault em relação aos saberes impostos pela sociedade, e também problematiza questões relacionadas à binaridade e suas simplificações homem $\mathrm{x}$ mulher, masculino $\mathrm{x}$ feminino, em que estavam enraizados padrões sociais criticados por Butler (2003) pelas "perfomatividades":

Se a verdade interna do gênero é uma fabricação e se um gênero verdadeiro é uma fantasia instituída e

18 "Trata-se de um termo muito questionado e que é, algumas vezes, utilizado como se fosse o mesmo que desconstrução. Entre os pensadores-chave associados com o pósestraturalismo estão Jacques Derrida, Paul de Man e Michael Foucault. A crítica desconstrutivista tenta solapar as bases da metafísica ocidental, ao questionar e dissolver oposições binárias". (SALIH, 2012, p. 34).

19 “Em 1987, Larry também fundou o Aids Coalition to Unleash Power (ACT UP), grupo que desafiou os discursos dominantes construídos pelo governo e autoridades científicas contra a estigmatização gay e que se notabilizou pela radicalidade conferida às suas manifestações" (PEREIRA; NICHIATA, 2009, p. 251). 
escrita sobre a superfície dos corpos, então parece que os gêneros não podem ser nem verdadeiros nem falsos, mas são apenas produzidos como efeitos de verdade de um discurso de identidade primária e estável. (BUTLER, 2003, p.195)

Butler (2003) apresenta a performatividade, também, ao analisar o movimento drag, destacando pontos importantes em relação à arte, à cultura e às questões sociais que circunscrevem o movimento social. Seguindo a linha de raciocínio apontada por Butler, deve-se analisar que a drag, em sua essência, reproduz um comportamento socialmente construído como feminino ao representar algo que teoricamente seria uma imitação do gênero que se pretende performar. Dessa forma, constata-se que a imitação já está internalizada, socialmente, no sujeito de tal maneira, que toda aquela representação tende a ser autêntica e o desejo de torná-la real, mesmo que somente para paródia, como no caso das queens, contudo, constrói-se uma narrativa que extrapola o que se entende como feminino. $\mathrm{O}$ exagero faz parte da arte drag. Assim, o feminino apresentado não cabe na ideia comum de mulher, pois, na arte, vai além, ultrapassa a ideia ética e estética de mulher para algo inusitado, uma feminilidade extravagante tomada de elementos sígnicos com sentidos que se transformam em cada corpo e em cada cena drag.

\section{A Identidade de Pabllo Vittar Inserida nas Novas Formas de Consumo Pós-Modernas}

Nota-se a clara distinção que Pabllo Vittar emprega em seu discurso quando diferencia a sua drag de sua identidade como sujeito: "Eu sou um menino, que amo ser menino (...) $\mathrm{E}$ amo fazer $d r a g$, eu tenho certeza que o drag sempre foi a extensão da minha personalidade" (VITTAR, 2018, 5 min), diz Pabllo Vittar em entrevista para o programa Conexão Repórter. Embora muitas vezes essas duas partes que a compõem ocupem o mesmo corpo território, corpo tomado de sentidos, de narrativas sensíveis, que produz sentido por suas imagens, suas vivências, da mesma forma que provoca interferência nas paisagens que atravessa pela imagética que o construiu, corpo em perfomatividade de imagens prismáticas. Pelo entendimento de tal processo, e com enfoque no objeto proposto neste artigo, faz-se necessário um estudo mais profundo sobre Pabllo além de seu desempenho artístico. Essa relação sobre o que se faz e o que se é como ser social para além da pessoa pública pode nos levar a interpretar mais facilmente o que Pabllo representa para os integrantes da comunidade LGBTQIA+ por meio dos diversos enquadramentos que envolvem sua identidade performática $\mathrm{e}$ sua carreira artística.

Durante a adolescência, Pabllo fez pequenas aparições em programas locais no seu estado de origem, o Maranhão, como no "Programa POP"20, um menino que ainda não se identificava como drag. A imagem apresentada negava, pelos prismas que buscava evidenciar, a base de uma identidade construída por signos da masculinidade, ou que apenas questionava padrões

\footnotetext{
${ }^{20}$ Programa apresentado por Thiago Miranda e produzido pela TV Difusora de Caxias. Disponível

<https://www.youtube.com/watch?v=InGq50

OPZJ4>. Acesso em: 21 de setembro de 2018.
} 
de dicotomia de gênero. A voz de Pabllo é desafiadora aos padrões esperados para a masculinidade, uma voz fina e que explora maneirismos e ajudam a adornar sua imagem. Outros vídeos da cantora circulam pela internet em sua fase de amadurecimento profissional e pessoal. Na metáfora de Louro (2008), em sua viagem ao encontro de uma identidade.

\begin{abstract}
Uma viagem é definida, no dicionário, como um deslocamento entre lugares relativamente distantes e, em geral, se supõe que tal distância se refira ao espaço, eventualmente ao tempo. Mas talvez se possa pensar, também numa distância cultural, naquela que se representa como diferença, naquele ou naquilo que é estar no "outro" distanciado e longínquo. A metáfora da viagem interessa-me para refletir não apenas sobre os percursos, as trajetórias e o trânsito entre lugares/culturas ou posições-de-sujeito, mas também para refletir sobre partidas e chegadas. Importa-me o movimento e também os encontros, as misturas, os desencontros. (LOURO, 2008, p.12)
\end{abstract}

Toma-se a metáfora de Louro (2008) sobre viagem para observar o percurso transgressor de Pabllo Vittar durante sua carreira artística, desde a primeira aparição, quando ainda jovem, até o momento em que atualmente se encontra, dando voz à sua drag. Notam-se pontos de partida e movimentos para o alcance do ponto de chegada. Este último continua não definido, sofrendo mudanças, ou ressignificações, como costuma ser frequente no mundo artístico.
Pabllo, nome socialmente tido como masculino, também é o nome utilizado para a construção da drag. Essa dualidade manifestada não só no nome, mas também no comportamento da artista, tem relação com um campo contrassexual, no qual o conceito determinista heteronormativo é ignorado. Diante da pluralidade de possibilidades de sexualidades declarada por Preciado no Manisfesto Contrassexual (2017), é precoce o enquadramento de Vittar dentro da identidade contrassexual, mas podemos nos apropriar das metáforas utilizadas pelo autor para construir relações interessantes entre a contrassexualidade e a performance da artista em questão.

De acordo com Preciado (2017), em seu manifesto, o orgasmo sexual é definido como uma reação natural construída ideologicamente dentro de um regime heterocentrado. Tal prática é habitualmente parodiada dentro das condições em que vive a sociedade contrassexual, assim com o objetivo de subverter a produção de prazer. Preciado (2017) faz diferenciações entre a construção do orgasmo feminino e do masculino ao longo da história: o orgasmo feminino era inicialmente visto como uma "crise de histeria" que foi condenada pela igreja e posteriormente definida como patologia pela medicina. Desse modo, observa-se por outro lado a performance de Pabllo, uma drag queen que subverte a normalidade do feminino quando está 
em cena, quando está tucking ${ }^{21}$, ou seja, mostrando sua "vagina". O que é uma drag, senão a paródia? Para Louro (2008, p. 20), "a drag escancara a construtividade de gênero". De acordo com a autora, a figura é desordeira e provoca desconforto e fascínio ao mesmo tempo: "Para as fronteiras constantemente vigiadas dos gêneros e da sexualidade, a crítica paródica pode ser profundamente subversiva. Em sua 'imitação' do feminino, uma drag queen pode ser revolucionária" (LOURO, 2008, p.20).

Nessas condições, põe-se em dúvida o prazer sexual como a única viabilidade de satisfação. Preciado (2017) descontrói, por exemplo, a teoria sobre os supostos órgãos sexuais, mais especificamente o pênis, como eixo central da produção de prazer, em sua metáfora com o dildo, que descreve ser para os contrassexuais uma entidade possibilitadora de saciedade. No caso das drags, o pênis é o órgão a não se evidenciar durante a performance. O corpo drag busca prazer na vagina inventada, mesmo que ela não seja penetrável. De todo modo, esse não é o objetivo da vagina drag. Preciado (2017) descreve que o dildo não necessariamente precisa ser representado em uma forma fálica, como, por exemplo, aqueles que "têm a forma de

\footnotetext{
21 Tucking é uma expressão comum no meio drag, também chamado de "esconder a neca" (pênis). Na arte drag, é comum que o pênis e os testículos sejam escondidos. O pênis é colocado para a parte traseira e os testículos, para dentro da cavidade na região da virilha, para que, dessa forma, a artista pareça ter uma vagina. Esse processo é comum para as drags que tenham pênis.
}

porco, de borboleta ou de sereia, ou que simplesmente não são figurativos" (PRECIADO, 2017, p. 71). E se utilizarmos o artifício de ressignificação dos corpos, como tucking, para entender o momento em que a drag atinge o auge de sua apresentação? O clímax de um longo processo que consiste em se montar $^{22}$ e preparar-se para viver a glória no pico de seus excessos: "Quando eu estou montada, parece que eu recebo um alterego" (VITTAR, 2018, $14 \mathrm{~min})^{23}$. Pode-se atribuir genuinidade em ambos os processos que são passíveis de serem utilizados para buscar prazer e satisfação pessoal. $\mathrm{O}$ prazer pode estar em qualquer parte do corpo, no corpo como um todo, logo, o prazer pode estar na montação, o orgasmo pode ser o momento da maquiagem, de andar com o salto, de bater cabelo, ou mesmo no momento do lipsync $^{24}$ de uma apresentação.

\footnotetext{
${ }^{22} \mathrm{O}$ termo é referente ao processo de preparo da personagem. Louro conta sobre a experiência em que acompanhou uma drag em seu "surgimento". "É no camarim que ela "se monta'. A 'montaria' consiste na minuciosa e longa tarefa de transformação de seu corpo, um processo que supõe técnicas e truques (como uma cuidadosa depilação, a dissimulação do pênis ou, ainda, por exemplo, o uso de seis pares de meias-calças para 'corrigir' as pernas finas) [...] sapatos de alta plataforma e que se complementa com pesada maquiagem (corretivo, base, batom, muito blush, cílios postiços e perucas)." (LOURO, 2008, p. 78).

${ }_{23}$ Disponível em: < https://www.youtube.com/watch?v=XFEXjAy w9t8\&t=331s>. Acesso em: 2 de setembro de 2018.

${ }^{24}$ Termo utilizado para descrever a prática que consiste em uma sincronia labial, ou dublagem. Esse artifício é muito utilizado pelas drag queens em suas apresentações.
} 
Representatividade como Protagonista na Criação de Campanhas Publicitárias: Pabllo Vittar Representando a "Quem Disse, Berenice?"

Tendo a publicidade como uma das formas de representação das identidades que compõem o corpo social, propõe-se avaliar o quanto as representações, neste caso, como as construções das imagens nas peças publicitárias, podem apresentar performatividades positivas para representatividades de grupos sociais ainda marginalizados por parcelas da população conservadora e por representantes do poder público. Tal proposição é colocada aqui no sentido de acreditar que expor essas narrativas midiaticamente implique uma convivência mais harmoniosa, e também colabore com o processo de reconhecimento das diversidades das mais variadas formas de ser/estar no mundo perante a esfera pública quando se trata de narrativas performativas transgressoras. Nessa ambiência, as empresas se colocam em uma linha tênue entre as suas próprias convicções e a representação dos mais diversos anseios de seus públicos; em muitas oportunidades, a decisão é geradora de conflitos, como, por exemplo, na campanha elaborada pelo 'O Boticário' para o dia dos namorados em 2015. O vídeo "Casais" "25, ou em outras campanhas surgidas no mesmo contexto de defesa da diversidade, como a "Pense

$25 \quad$ Disponível em: $<$ https://www.youtube.com/watch?v=p4b8 BMnolDI $>$. Acesso em: 02 de outubro de 2018.
Menos, Ame Mais"26 da Sonho de Valsa, "Dia das Mães - Gilberto e Rodrigo $^{27}$ " da Gol, ou ainda o anúncio postado $^{28}$ pela 'Close Up' em suas redes sociais que mostra dois homens prestes a se beijar, ajudam a compor um cenário favorável para a representação cada vez mais frequente da comunidade LGBTQIA+ na publicidade. Hoje, pode-se notar mais empresas que fornecem espaços de visibilidade para a diversidade, alguns preenchidos pelo objeto de estudo dessa pesquisa, Pabllo Vittar.

De acordo com as mudanças de relação e interação dos consumidores da sociedade pós-moderna, julga-se importante para o mercado publicitário adequar-se às tendências e aos novos desejos desses consumidores, não só na reta final do consumo desse produto, que seria julgado pelo ato de compra, mas também nos processos contemporâneos de relacionamento com esse consumidor, que geralmente iniciam-se antes do ato de consumo, e também na fidelização desse cliente após a experiência compartilhada com a marca. De acordo com a teoria de Kotler, Kartajaya e Setiawan (2017), vem se tornando mais importante a postura desse consumidor em compar-

26 Disponível em: <https://www.youtube.com/watch?v=HYWyz YJhQyk>. Acesso em: 28 de setembro de 2018.

27 Disponível em: <https://www.youtube.com/watch?v=Co6Oe9PRqY>. Acesso em: 28 de setembro de 2018. ${ }^{28}$ CLOSEUP publica foto de beijo gay e divide opiniões. Disponível em: <https://extra.globo.com/noti cias/economia/closeup-publica-foto-de-beijogay-divide-opinioes-na-web-17532556.html> . Acesso em: 28 de setembro de 2018. 
tilhar suas opiniões, influenciando, assim, outros consumidores a se aproximarem da marca. A principal fonte de pesquisa, na era da conectividade, é a comunidade social.

Tal traspassamento ocorre em diversas campanhas publicitárias, como a que aqui se pretende analisar. Em busca desse envolvimento do consumidor por todos os canais, é bemvindo elaborar estratégias nas quais esses diversos meios de comunicação conversem entre si, mostrando-se uma das facetas da convergência. $\mathrm{O}$ conceito de transmídia é uma dessas possibilidades; este é definido por Jenkins (2006) como uma dinâmica que se utiliza de vários elementos para transmitir uma mensagem.

Uma história transmídia desenrolase através de múltiplas plataformas de mídia, com cada novo texto contribuindo de maneira distinta e valiosa para o todo. Na forma ideal de narrativa transmídia, cada meio faz o que faz de melhor - a fim de que uma história possa ser introduzida num filme, ser expandida pela televisão, romances e quadrinhos; seu universo possa ser explorado em games ou experimentado como atração de um parque de diversões. (JENKINS, 2006, p. 138).

A inserção da marca 'Quem disse, Berenice?' no clipe da música Disk Me, de Pabllo Vittar, mostra um pouco dessa relação transmídia, permite a análise aplicada desse conceito e será debatida em um tripé que tem como bases a artista, a marca e o público. A empresa 'Quem disse, Berenice?', integrante do Grupo O Boticário, foi fundada em 2012, e desde então preza pela liberdade de escolha dos seus consumidores. Os valores de desconstrução de padrões não se limitam somente ao nome da marca - que, ao indagar "Quem disse?", contraria um saber tido como normativo, um padrão estabelecido -, mas se expandem por toda a linha de produtos, estratégias de marketing e publicidade e também acompanham o discurso no site institucional da empresa ${ }^{29}$. Para a 'Quem disse, Berenice?', ser livre para fazer escolhas é um direito de experimentar o mundo e suas diversas possibilidades.

Percebe-se o grande desafio dos publicitários e marqueteiros ao lidarem com os consumidores pósmodernos, que buscam cada vez mais estreitar um laço que transita pelo campo dos afetos, tornando esses consumidores mais íntimos e estabelecendo um relacionamento amigável. Percebe-se, nesse sentido, uma relação afetual, uma construção de laço, de vínculo, por (auto)reconhecimento do consumidor diante das narrativas propostas pelas campanhas e, conseguintemente, pelos posicionamentos e pela construção da imagem das marcas nos novos cenários contemporâneos. Ao conquistar essa proximidade, um objetivo maior do que a ação de compra é alcançado pela marca. Segundo Kotler, Kartajaya e Setiawan (2017), a empresa ganha nesse momento um aliado que irá advogar em nome da marca e, além de indicar seus produtos, defenderá sua reputação quando necessário.

29 Disponível em: $<$ https://www.quemdisseberenice.com.br/instit ucional/sobre-a-quem-disse-berenice>. Acesso em: 25 de outubro de 2018. 
Ainda segundo Kartajaya e Setiawan (2017, p. 6): "além disso, os advogados de marcas são também contadores de histórias que espalham notícias sobre as marcas pelas suas redes. Eles contam histórias autênticas do ponto de vista do cliente - um papel que a publicidade nunca poderá substituir".

A publicidade é um espaço possibilitador de representatividade, e as marcas que se propõem a abrir seus espaços para as comunidades que carecem dessa atenção tendem a conquistar algo maior do que o estado de amor dos seus consumidores e podem construir pontes definitivas para determinados sujeitos se apresentarem diante da sociedade, "se empoderando" e até mesmo evidenciado os produtos e a marca. Faz-se necessária uma congruência em relação às atitudes dessas empresas, pois a "publicidade não faz nada sozinha e só funciona quando tem como missão enaltecer qualidades reais" (VIEIRA, 2014, p.139). Nesses moldes, é válido creditar as atitudes de marcas que venham caminhando sem tropeços éticos em direção a um posicionamento que inclui narrativas que se ausentaram por determinado tempo. É importante que o posicionamento ideológico sobressaia aos demais questionamentos impostos pela sociedade sobre o lucro, mais precisamente, à exploração do tão debatido pink money ${ }^{30}$. Principalmente, quando a própria comunidade reconhece esse espaço de representatividade, que foi negociado, desejado e por muito tempo reivindicado, como

${ }^{30}$ Expressão utilizada para se referir ao poder aquisitivo da comunidade LGBTQIA+. fator observado ao longo desta pesquisa, que buscou apontar a representatividade vista como positiva aos olhos da comunidade LGBTQIA+, por ser ferradora de identificação, reconhecimento social nas imagens veiculadas.

A importância desse espaço de representação é imensurável. Suas consequências já se mostram evidentes no corpo social, quando temos, por exemplo, uma drag queen ocupando espaços jamais destinados ao mix de gênero e cultura. $\mathrm{O}$ objeto de estudo desta pesquisa, Pabllo Vittar, demonstra-se cada vez mais capaz de representar o grupo social que lhe confia tal responsabilidade: a comunidade LGBTQIA+.

Observou-se na campanha 'Quem disse, Berenice?', inserida no clipe Disk Me, de Pabllo, as mais variadas possibilidades de contato com os consumidores, que viabilizam diferentes formas de engajamento, por meio de canais comunicacionais, e que potencializam a construção de conhecimento coletivo e coparticipação do consumidor. Observa-se o poder dos "advogados" da marca e de Pabllo Vittar junto aos integrantes LGBTQIA+ e às pessoas que acompanham a drag pelas redes sociais, pela publicidade midiática.

Diante de todos os fatores aqui identificados, evidencia-se a importância de narrativas publicitárias mais inclusivas e representativas das diversas fragmentações identitárias que compõem a pós-modernidade. Os benefícios que acompanham essa atitude podem atingir diversos sujeitos que anseiam por ocupar cenários que sempre lhes foram negados, como o caso 
da comunidade LGBTQIA+ e também podem ser uma estratégia assertiva para as marcas que topam conceder esses espaços. Logo, é necessário que nós, profissionais de comunicação, estejamos atentos a essa questão, que exige um olhar mais sensível na identificação de histórias que merecem ser incluídas nos presentes e futuros projetos. 


\section{Referências}

AMANAJÁS, I. Drag queen: um percurso histórico pela arte dos atores transformistas. São Paulo: Publicação online, 2015. Disponível em: $<$ http://www.belasartes.br/revis tabelasartes/downloads/artigos/16/drag-queen-umpercurso-historico-pela-artedos-ato res-transformistas.pdf $>$. Acesso em: 14 de abril de 2018.

BAILEY, M. M. Butch Queens Up in Pumps: Gender, Performance, and Ballroom Culture in Detroit. Michigan: The University of Michigan Press, 2013.

BAKER, R. Drag: A History of Female Impersonation in the Performing Arts. Nova Iorque: New York University Press, 1994.

BERTHOLD, M. História mundial do teatro. São Paulo: Perspectiva, 2004.

BUTLER, J. Problemas de gênero. Feminismo e subversão da identidade. Rio de Janeiro: Civilização Brasileira, 2003.

HALL, S. A identidade cultural na pós-modernidade. Tradução Tomaz Tadeu da Silva, Guacira Lopes Louro. Rio de Janeiro: DP\&A, 2006.

HUGHES, L. The Big Sea: an autobiography. Nova Iorque: Hill and Wang, 1993, 2nd edition, 1993, 335 p.

FOUCAULT, M. História da sexualidade I: a vontade de saber. Rio de Janeiro, Edições Graal, 1988.

JENKINS, H. Cultura da convergência: a colisão entre os velhos e os novos meios de comunicação. São Paulo: Aleph, 2006.

JESUS, J. G. de. Orientações sobre identidade de gênero: conceitos e termos. Brasília: Publicação online, 2012. Disponível em:<http://www.sertao. ufg.br/up/16/o/ ORIEN-

TA\%C3\%87\%C3\%95ES_POPULA\%C3\%87\%C3\%83O_TRANS.pdf?1334\%20065 $989>$. Acesso em 07 de setembro 2018.

KOTLER, P.; KARTAJAYA, H.; SETIAWAN, I. Marketing 4.0. Do tradicional ao digital. São Paulo: Sextante, 2017.

LOURO, G. L. Um corpo estranho: ensaios sobre sexualidade e teoria queer. Belo Horizonte: Autêntica, 2008. 
O BOTICÁRIO. Site Institucional. Disponível em: <www.boticario.com.br〉. Acesso em: Acesso em: 10 de outubro de 2018.

PEREIRA, A. J. \& NICHIATA, L. Y. I. A sociedade civil contra a Aids: demandas coletivas e políticas públicas. Ciência \& Saúde Coletiva, v. 16, n. 7, p. 3249-3257, 2011. Disponível em: 〈http://www.scielo.br/pdf/csc/v16n7/24.pdf〉. Acesso em: 20 de outubro de 2018.

PRECIADO, P. B. Manifesto contrassexual. Tradução Maria Paula Gurgel Ribeiro - São Paulo: n-1 edições, 2017.

'QUEM DISSE, BERENICE?'. Site Institucional. Disponível em: < https://www.quem disseberenice.com.br>. Acesso em: 10 de outubro de 2018.

SALIH, S. Judith Butler e a teoria queer. Tradução Guacira Lopes Louro. Belo Horizonte: Autêntica, 2012.

SANTOS, H. C. A transnacionalização da cultura dos Ballrooms. São Paulo: Publicação online, 2018. Disponível em: <http://repositorio.unicamp.br/bitstream/ REPOSIP/331699/1/Santos_HenriqueCintra_M.pdf>. Acesso em: 20 de julho de 2018.

SPARGO, T. Foucault e os estudos queer. Belo Horizonte: Autêntica, 2017.

VENUTI, L. Escândalos da Tradução. Tradução Stella Tagnim. Edusc, 2011.

VIEIRA, S. Marca: o que o coração não sente os olhos não veem. 11. ed. - São Paulo: Editora WMF Martins Fontes, 2014.

\section{Filmografia:}

PARIS IS BURNING. Direção: Jennie Livingston. EUA: Art Matters Inc. e Miramax, 1990. 71min (DVD). Son, Col, Inglês.

O(s) autor(es) se responsabiliza(m) pelo conteúdo e opinióes expressos no presente artigo, além disso declara(m) que a pesquisa é original.

Recebido em 07/03/2020

Aprovado em 23/06/2020 